\title{
Test failures may hold up space shuttle schedule
}

Mechanical failures during experimental testing of the main engines are threatening to hold up the National Aeronautics and Space Administration's Space Shuttle programme, the first orbital launch of which is scheduled to take place next year.

Three separate test failures have been attributed to problems with turbine blades in the engine's high pressure fuel pump. In two cases the blades were fractured or cracked, and in the third the evidence was destroyed in a fire which followed the malfunction.

Dr Robert A. Frosch, administrator of NASA, said last week that despite the setbacks to the engine testing programme, the agency still had full confidence in the basic design of the engine, and was optimistic that the Space Shuttle programme would proceed broadly on schedule.

However, he admitted that the likelihood of achieving the initiallyscheduled March 1979 date for the first manned orbital flight was "considerably less than 50-50", and that the chances of meeting the June deadline to which the agency is now planning were "about two to one in favour".

Dr Frosch's remarks were made in response to a report on the problems of the Space Shuttle engines which had been prepared, at the request of the Senate Committee on Commerce, Science and Transportation, by an ad hoc committee of the National Research Council, under the chairmanship of Professor Eugene E. Covert of the Massachusetts Institute of Technology

In its report, the NRC committee says that it is confident that the programme will be a success, and that although the development of the engine is not as far along as the timetable might suggest, the problems being encountered were not alarming, but rather typified the early stage of any similar new technological development. And the committee makes various technical suggestions about how some of the problems might be overcome.

However, the committee adds that achieving acceptable solutions could result in delays to the programme, and that "the ambitious timetable may have to be extended to avoid a first manned orbital flight with a high risk factor."

Furthermore it suggests that some of the problems may have arisen as a result of the heavy pressures under which the Space Shuttle programme is being carried out. In particular these have lead to the choice of a "successorientation", in which every step depends on the success of a number of separate developments each tested in isolation, with little investigation of alternative solutions to particular problems.

Referring to the malfunctioning of the engines during tests, the committee expresses a concern that "the current schedule is so compressed it generates an atmosphere that seems to inhibit realistic evaluations of the problems encountered so far." And it urges NASA to "adhere to currently established testing criteria and standards in spite of the pressures imposed by an ambitious schedule."

The novel and demanding requirements of the Space Shuttle enginethat it should be both capable of propelling an orbital space craft and reusable on a number of successive flights-have necessitated major developments in engine design that the NRC committee recognise as a "prodigious engineering challenge."

The engine provides power by converting liquid hydrogen and liquid oxygen into superheated steam as a propellant. And a major cause for concern has been that during tests the engine has burned at considerably higher temperatures than originally planned.

These higher temperatures are thought to have led to the failure of the turbine blades, which are made of a nickel-based alloy MAR-M-246 originally selected as providing the best performance at a planned temperature around $1250{ }^{\circ} \mathrm{F}$, rather than the $1500^{\circ} \mathrm{F}$-with brief peaks up to $2100^{\circ} \mathrm{F}$-actually experienced.

NASA is still hoping to be able to reduce the temperature and the vibratory stresses in the engine to a level which will allow such blades to be used. However, Rocketdyne Corporation, which is developing the engine under contract, announced at hearings of the Senate Committee in Washington last Friday that it is now conducting tests on other materials as a precautionary measure.

If it proves necessary to select a new blade material or to make other major design modifications--such as strengthening the shaft and housing-the rerequisite tests could take up to two years. And this would cause serious delays for the Space Shuttle programme, including the European Space Agency's Spacelab, at present scheduled for launch in 1980.

Such delays would also have embarrassing political consequences for a project whose cost-effectiveness has in the past come in for considerable Congressional criticism, and which President Carter has already tried to cut back by reducing the number of orbiters from five to four.

NASA remains optimistic that the technical difficulties encountered by the engine can be overcome without serious difficulty, and Dr Frosch disputes the NRC committee's criticism of the way that the project is being managed.

However, the agency has agreed to take a long, hard look at the proposed schedule as soon as data is available from the series of engine tests which it intends to carry out over the next few months. And given that its materials' scientists are working at the leading edge of technical knowledge, and that it recognises the fineness of the margin which could separate success from failure, many fingers are remaining tightly crossed.

David Dickson

\section{China's science has 20 years to catch up}

China has announced an eight-year crash plan to catch up on the rest of the world in scientific research. Details were given by Vice-Premier Fang $\mathrm{Yi}$ to the giant All-Nations Science Conference which opened in the Great Hall of the People, Peking last month.

The 6,000 delegates were told that China was at least 15 to 20 years behind the advanced world in many branches of science and still more in others. The aim was to narrow this gap to 10 years in a number of im- portant branches by 1985 . This would then be a solid foundation for catching up with and overtaking the rest of the world in all branches of science by the end of the century.

Fang $\mathrm{Yi}$ was unveiling the draft Outline National Plan for the Development of Science and Technology 19781985, which has been drawn up by the recently reconvened State Scientific and Technological Commission. In the next eight years China will increase the number of professional research workers to 800,000 , build research centres with "state of art" facilities and complete a nationwide system of research and development based on these centres.

The plan covers 27 disciplines, gives prominence to eight research fields (see panel) and identifies 108 "key projects".

Fang $\mathrm{Yi}$ also opened the door to academic exchanges with other countries. The Chinese, he said, will combine learning from other people 
with their own inventiveness. They would like to invite foreign scientists and technical experts to China to give lectures, teach and join them in research.

Earlier, the country's Vice-Chairman, Teng Hsiao-ping, said that China should trust those engaged in scientific work because "generally speaking the overwhelming majority of them are part of the proletariat"

His opening speech to the conference gave full weight to the importance of science and technology. It was tightly bound up with production and was a positive force in advancing society, said Teng. Teng equated dedicated scientists with dedicated revolutionaries and announced China's intention of building "a mighty army of young scientists". This would be done by breaking with convention on the educational front so that selection and training could be achieved in the shortest possible time. Success was possible, he said, because "an extensive mass base can provide a continuous flow of talent". This echoed a statement in a party circular issued last year which said: "Scientific experiments in our country [combine] efforts by both the professionals and the masses. This is something no [western] country has done or can do. Such great mass

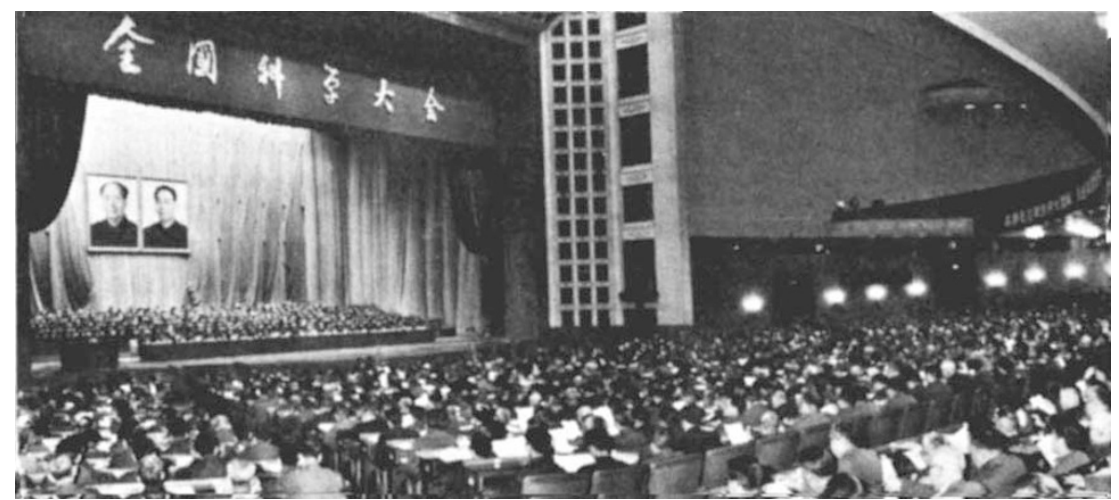

Great Hall of the People: planning to overtake the world

movements will open inexhaustible springs of creativity".

Teng promised some relaxation of political control over scientific work. The party would continue to provide leadership but its focus would have to change. One example was the reintroduction of research directors whose positions were downgraded under the rule of the Gang of Four.

The political theme was taken up by Chairman Hua when he addressed the conference. Scientists should continue raising their political consciousness while combining their personal effort with collective wisdom in their research. They would then speak a common language with the workers.
China was training "hundreds of millions of working people" who would combine mental with manual labour, people who would be both workerintellectuals and intellectual-workers. Hua called for a general rise in the scientific level of the masses which would provide "the base and conditions of growth for the professionals, who for their parts will guide the mass forces, crystallise their experience and wisdom and raise it to a higher level". The world, Hua said, had witnessed differert roads to modernisation but what China wanted was socialist modernisation, something which perhaps had not so far been seen.

T. B. Tang
AGRICULTURE. Comprehensive surveys to study the rational exploitation of land resources and the protection of the ecological system. Research devoted to developing a farming system and cultivation techniques which combine both intensive farming and mechanisation. Solutions sought for scientific and technical problems associated with a hydrological project to divert water from the south to the north. Special attention for crop growth on alkaline, lateritic, clay and other types of poor soil, since they account for one-third of the country's total farmland.

ENERGY. Research on gasification, liquefaction, and multi-purpose uses of coal. China is already advanced in petroleum geology and technology; a key project will therefore be investigation of the genesis and distribution of oil and gas, together with the development of new crude oil processing techniques. Other efforts: hydroelectricity generation, solar energy, geothermal, wind, tidal, and thermonuclear fusion power, and energy conservation and the utilisation of wastes in major industrial processes.

\section{Research: China's eight priorities}

MATERIALS. Pinpointed areas include metallurgy of special steels, and the refining of copper, aluminium, nickel, cobalt, titanium and vanadium, and the rare-earth metals. Emphasis is on high polymer science, organic synthesis, and catalysis.

COMPUTERS. China aims to put a range of fast main-frames into production shortly and to establish a strong computer network and data base by 1985 . Peripherals, software and the associated areas of applied mathematics to receive balanced attention. While speeding up the mass production of LSI's, a special effort will be made to make a breakthrough in the technology of ultra-large-scale integrated circuits. Minicomputers and microprocessers will be introduced.

LASERS. More research in laser spectroscopy and non-linear optics to back up the scientific application of laser. New lasing mechanisms will be investigated, more tunable lasers de- veloped and applications such as isotope separation fully looked into. High-power installations will be constructed to study laser-triggered fusion. China is also interested in laser communication.

SPACE. Efforts devoted to basic space physics, cosmic rays, and the technical problems of remote sensing. A series of skylabs, deep-space and communication satellites will be launched within eight years.

HIGH-ENERGY PHYSICS. A 50$\mathrm{GeV}$ proton accelerator to be completed in five years and up-dated to still higher energy in the next five. An extensive experimental base will be built around this key research centre to serve agriculture, industry, medicine, and other spheres.

GENETIC ENGINEERING. China is weak in this new field and will spend the first three years mainly on basic studies. By 1985 she hopes to have fully integrated the subject with molecular genetics and cell biology, and be working on its potential use to treat certain diseases and to fix nitrogen biologically. 